\title{
A Cluster-Randomized Controlled Trial Evaluating the Effects of Mass Azithromycin Treatment on Growth and Nutrition in Niger
}

Abdou Amza, Boubacar Kadri, Baido Nassirou, Nicole E. Stoller, Sun N. Yu, Zhaoxia Zhou, Sheila K. West, David C. W. Mabey, Robin L. Bailey, Jeremy D. Keenan, Travis C. Porco, Thomas M. Lietman, and Bruce D. Gaynor*

Université Abdou Moumouni de Niamey, Programme National de Lutte Contre la Cécité, Niamey, Niger; F. I. Proctor Foundation, Department of Ophthalmology, Department of Epidemiology and Biostatistics and Institute for Global Health, University of California, San Francisco, California; Center for Infectious Disease and Emergency Readiness, University of California, Berkeley, California; Dana Center for Preventive Ophthalmology, Wilmer Eye Institute, Johns Hopkins University, Baltimore, Maryland; Clinical Research Unit, Department of Infectious and Tropical Diseases, London School of Hygiene and Tropical Medicine, London, United Kingdom

\begin{abstract}
Antimicrobials are used primarily to treat infectious disease, but they have other effects. Here, we assess anthropometry measurements in children 6-60 months in 24 communities randomized to one or two mass azithromycin distributions over a 1-year period in Niger. We compared the prevalence of wasting, low mid-upper arm circumference, stunting, and underweight in communities in the two treatment arms. We were unable to prove that there was a difference in the prevalence of wasting in the 12 communities that received one mass azithromycin distribution versus the 12 communities that received two mass azithromycin distributions (odds ratio $=0.75,95 \%$ confidence interval $=$ 0.46-1.23). Likewise, we were unable to detect a difference in the two treatment arms for low mid-upper arm circumference, stunting, and underweight. There may not be an association between antibiotic use and improved growth in humans, or this trial was not powerful enough to detect an association if it exists.
\end{abstract}

\section{INTRODUCTION}

Antimicrobials are used primarily to treat infectious diseases, although their effects are wide-ranging. A relationship between malnutrition and infection has long been recognized. ${ }^{1}$ In young children in developing countries, a high proportion of deaths from diarrhea, pneumonia, and malaria are attributable to undernutrition. ${ }^{2}$ In fact, malnutrition is thought to play a role in more than one-half of all childhood deaths worldwide caused by these conditions. ${ }^{3}$ Periodic treatment or prevention of these common childhood infections could theoretically improve growth and lower mortality in children. If so, this improvement would prove to be an important benefit of mass azithromycin treatments for trachoma.

Azithromycin has some activity against infections that lead to the three main causes of death in the developing world: pneumonia, ${ }^{4}$ diarrhea, ${ }^{5,6}$ and malaria. ${ }^{7}$ A case control ${ }^{8}$ and clusterrandomized clinical trial $^{9}$ showed that mass azithromycin treatments were associated with reduced mortality in children. However, if mass azithromycin treatments affect mortality, the mechanism by which they do so is unknown. We aim to investigate explanatory factors for mortality reduction by measuring anthropometric indices. Mass azithromycin treatments for trachoma provide a unique opportunity to study the effect of these treatments on growth and nutrition. The current investigation is a substudy of the Partnership for the Rapid Elimination of Trachoma (PRET), a cluster-randomized clinical trial (clinicaltrials.gov trial NCT00792922) investigating different treatment strategies for trachoma, an ocular infection with Chlamydia trachomatis. The study methods for PRET have been previously described and are summarized briefly below. ${ }^{10}$ We hypothesize that children ages 6-60 months in 12 communities randomized to biannual mass azithromycin treatment will have better growth and nutrition compared with children

* Address correspondence to Bruce D. Gaynor, F. I. Proctor Foundation, Department of Ophthalmology, University of California, 513 Parnassus, Med Sci 338B, San Francisco, CA 94143-0944. E-mail: bruce.gaynor@ucsf.edu in 12 communities randomized to annual mass azithromycin in a substudy of a cluster-randomized clinical trial in Niger.

\section{METHODS}

Study setting and design. The study took place in the Matameye district of the Zinder region of Niger. The district is divided into grappes (government health units) that are referred to as communities in this manuscript. Communities were selected from six health centers (Center de Santé Intégrée [CSIs]). Inclusion criteria were total population between 250 and 600 persons and prevalence of active trachoma (trachomatous inflammation - follicular [TF] and/or trachomatous inflammation - intense [TI] using the World Health Organization [WHO] system $)^{11} \geq 10 \%$ in children ages $0-60$ months. There were 235 eligible communities in the six CSIs, of which $72(31 \%)$ communities satisfied the inclusion criteria for size; 48 communities were randomly selected for the PRET study.

Community and individual randomization. The current substudy took place in May of 2011 in 24 communities randomized to two different mass antibiotic treatment strategies: annual treatment of everyone or biannual treatment of children $0-12$ years. Eligible individuals $>6$ months were offered their assigned treatment of a single directly observed oral dose of azithromycin (height-based dosing equaling $20 \mathrm{mg} / \mathrm{kg}$ ) in June or July of 2010. Children $<6$ months were offered topical tetracycline to be used two times daily for 6 weeks per the WHO recommendation. ${ }^{12}$ A second mass antibiotic treatment was offered to everyone in the biannually treated communities in December of 2010 or January of 2011. All outcome measurements were performed in a random sample of 50 children ages 6-60 months in each of the 24 communities based on the May of 2011 census. If the community did not contain 50 children, all children were included. Randomization of communities to the treatment arms and randomization of individuals within communities were done using RANDOM and SORT functions in Excel (version 2003) or the statistical package $R$ (version 2.12; R Foundation for Statistical Computing, Vienna, 
Austria; www.r-project.org) ${ }^{13}$ by B.N. and T.C.P. as previously described. ${ }^{14}$ Study teams monitored antibiotic treatment coverage levels in all communities at both treatments. Analyses were performed at the community level on an intention-to-treat basis, and no adjustments were made for missing or absent individuals.

Data collection and intervention and nutritional assessment. Before the trial, field workers attended a 2-day workshop, where the WHO training course on standard growth measurement procedures ${ }^{15}$ was administered under the supervision of study coordinators and researchers from the F. I. Proctor Foundation, University of California at San Francisco. We mea- sured recumbent length in children younger than 24 months or standing height in children older than 24 months when the child was able to stand to the nearest $0.1 \mathrm{~cm}$ (Shoreboard; Shorr Productions, LLC, Olney, MD). We subtracted $0.7 \mathrm{~cm}$ from the child's length to derive an estimated height when a child older than 24 months was too sick or weak to stand in accordance with the WHO conversion formula. ${ }^{16}$ Children were weighed standing when they were able at all ages or in the arms of a parent or guardian when necessary without clothing or with only light clothing to the nearest $0.1 \mathrm{~kg}$ (Seca 874 flat floor scale; Seca GMBH \& Co. Kg, Hamburg, Germany). Mid-upper arm

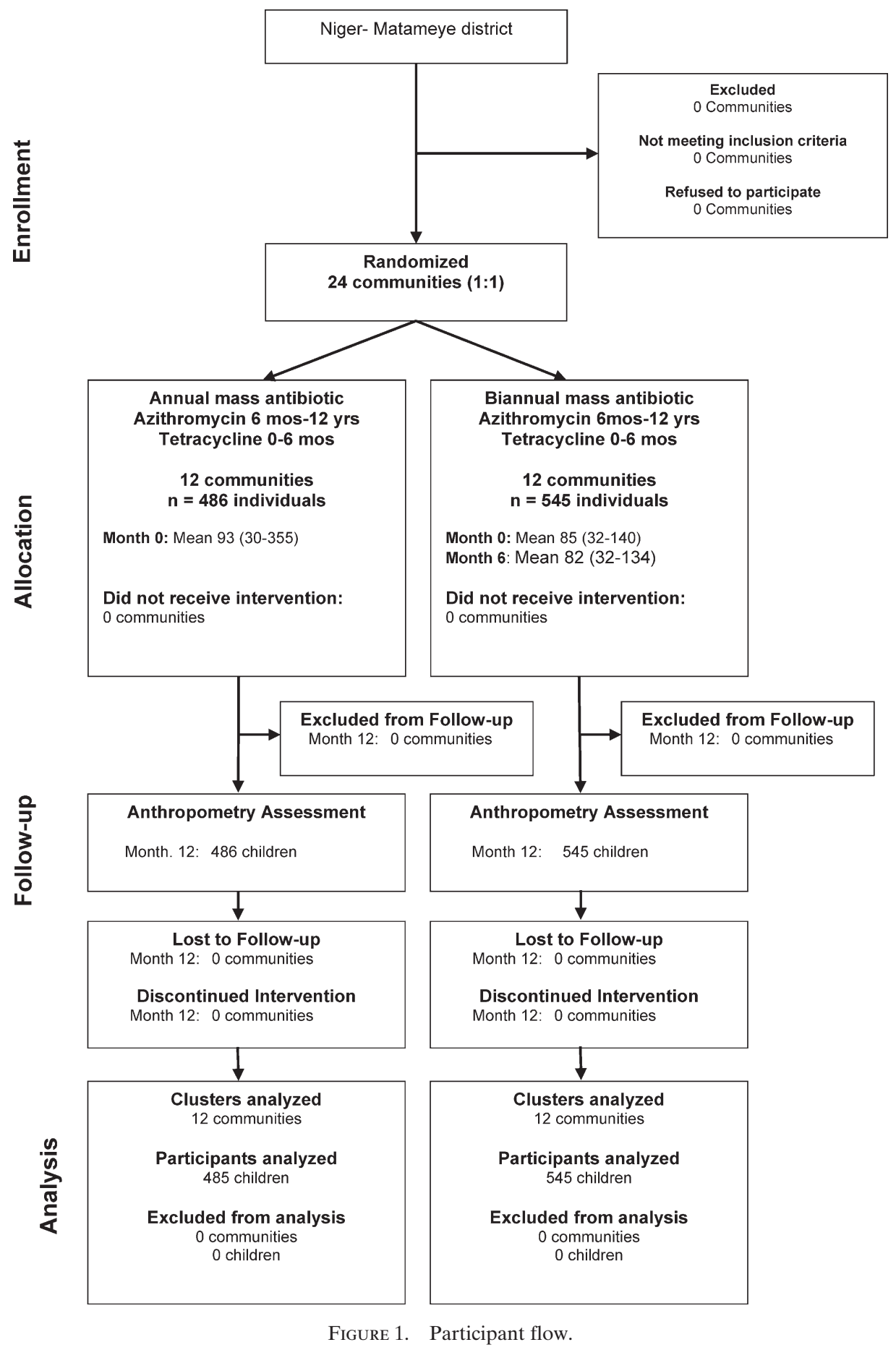


circumference (MUAC) was measured to the nearest $0.1 \mathrm{~cm}$ using a non-stretchable tape developed by Johns Hopkins University. ${ }^{17}$ All anthropometry measurements were done in triplicate by field workers trained to assess growth in infants and children, and median values were used for analyses. Calibration of height/length and weight measurements was done after every 10 th person. Field workers referred severely ill or malnourished children to local health posts for additional evaluation. Field workers were not informed of treatment allocation or antibiotic coverage at all visits. Community members were not masked to their treatment assignment.

Statistical analysis. We calculated age- and sex-adjusted community level nutritional $z$ scores for wasting (weightfor-height $z$ score [WHZ]), low MUAC (MUAC $z$ score [MUACZ]), stunting (height-for-age $z$ score [HAZ]), and underweight (weight-for-age $z$ score [WAZ]) using the WHO Anthro software program ${ }^{16}$ based on the WHO child growth standards. ${ }^{18}$ Low anthropometry was defined as $<-2.0 z$ scores of the median for the WHO reference population. ${ }^{19}$ We determined odds ratios for low anthropometry using mixed effects logistic regression with community as a random effect. We also assessed anthropometry measurements as continuous outcomes using mixed effects linear regression with community as a random effect. We calculated intraclass correlation coefficients (ICCs) using similar models. As an exploratory analysis, we compared community-level WHZ scores after restricting inclusion to participants who took their assigned treatment at baseline in all communities (mixed effects linear regression with community as a random effect). To determine if a dose-response relationship was present, we measured WHZ scores that restricted inclusion to participants who took their assigned treatment one time (baseline) or two times (baseline and 6 months) in the biannually treated communities. Finally, to confirm the presence of any dose response, we measured WHZ scores that restricted inclusion to participants who took their assigned treatment at baseline in the annually treated communities.

Assuming 50 children per village, $\alpha=0.05$, ICC $=0.015$ (from a clinical trial in Niger), ${ }^{20}$ and $8 \%$ prevalence of wasting (from a clinical trial in Niger), ${ }^{20}$ inclusion of 12 state teams per group would provide $80 \%$ power to detect an absolute difference of $6 \%$. We used the statistical package $\mathrm{R}$ (version 2.12) or STATA 11 (Stata Corp., College Station, TX) for all analyses. ${ }^{13}$

Human participants and consent procedures. Ethical approval for this study was obtained from the Committee for Human Research of the University of California, San Francisco and le Comité Consultatif National d'Ethique du Ministere de la Sante Publique, Niger (Ethical Committee, Niger Ministry of Health). Oral consent was obtained from the community leaders, and written (thumbprint) consent was obtained from the child's parent or guardian at the time of examination. The study was carried out in accordance with the Declaration of Helsinki.

\section{RESULTS}

A total of 48 communities were enrolled in PRET, with 12 communities randomized to annual treatment and 12 communities randomized to biannual treatment according to the study design (Figure 1). All communities received mass treat- ment in June and July of 2010, and the biannually treated communities received a second treatment in December of 2010 and January of 2011. There were 1,030 individuals (6-60 months) in the 24 communities in this anthropometry study (486 individuals in annually treated communities and 545 individuals in biannually treated communities). The mean antibiotic coverage of children ages $6-60$ months was $80.4 \%$ (95\% confidence interval $[\mathrm{CI}]=76.8-84.1)$ for the single treatment of the annually treated communities and $74.4 \%$ $(95 \% \mathrm{CI}=69.4-79.3)$ and $78.7 \%(95 \% \mathrm{CI}=74.6-82.7)$ for the two treatments in the biannually treated communities. Anthropometry measurements were performed in May of 2011, 10 or 11 months after treatment in the annual arm and 6 months after treatment in the biannual arm as per study design. Baseline characteristics, including average number of children per community, age of children, fraction female, and clinical trachoma prevalence, were similar in the communities randomized to the two treatment arms (Table 1). All communities received their scheduled treatments, and no community was lost to follow-up over the length of the study. There were no serious adverse events attributed to the study medicine reported through a passive surveillance system throughout the entire length of the study.

The odds of wasting were $25 \%$ less (odds ratio [OR] $=0.75$, $95 \% \mathrm{CI}=54 \%$ less to $23 \%$ more), low MUAC was $7 \%$ less ( $\mathrm{OR}=0.93,95 \% \mathrm{CI}=41 \%$ less to $46 \%$ more), stunting was $11 \%$ less $(\mathrm{OR}=0.89,95 \% \mathrm{CI}=35 \%$ less to $22 \%$ more $)$, and underweight was $19 \%$ less $(\mathrm{OR}=0.81,95 \% \mathrm{CI}=43 \%$ less to $16 \%$ more) in the biannually treated communities than the annually treated communities (mixed effects logistic regression with community as a random effect). The mean prevalence of severe wasting ( $\mathrm{WHZ}<-3.0)$ was not different in annually and biannually treated communities $(\mathrm{OR}=1.08$, $95 \% \mathrm{CI}=47 \%$ less to $222 \%$ more $)$. The ICC was $0.019(95 \%$ $\mathrm{CI}=0.000-0.043)$ for height and $0.022(95 \% \mathrm{CI}=0.000-0.050)$ for weight. In a linear model (mixed effects linear regression with community as a random effect), we were unable to detect a difference in anthropometry between the biannually treated communities and the annually treated communities (Tables 2 and 3).

With the analysis restricting enrollment to individuals who participated in the program and received their assigned antibiotic treatment at baseline, there was no significant change in the results for the association of antibiotic treatment and anthropometry in the logistic regression models for wasting, low MUAC, stunting, and underweight (data not shown). However, WHZ was $50 \%$ higher in the biannually treated

TABLE 1

Baseline characteristics of 24 communities randomized (1:1) to annual or biannual mass azithromycin treatment in a clusterrandomized clinical trial for trachoma in Niger

\begin{tabular}{|c|c|c|}
\hline & $\begin{array}{l}\text { Annual treatment } \\
\text { (12 communities) }\end{array}$ & $\begin{array}{l}\text { Biannual treatment } \\
\text { (12 communities) }\end{array}$ \\
\hline $\begin{array}{l}\text { Children per community } \\
<60 \text { months }\end{array}$ & $124(42-207)$ & $118(88-147)$ \\
\hline Age of children (months) & $30.8(29.8-31.9)$ & $31.9(30.7-33.0)$ \\
\hline Proportion female & $51.3 \%(48.2-54.4)$ & $50.1 \%(47.1-53.1)$ \\
\hline Prevalence trachoma $\mathrm{TF}^{*}$ & $26.5 \%(14.9-38.0)$ & $24.1 \%(15.9-32.3)$ \\
\hline Prevalence trachoma TI* & $8.6 \%(4.4-12.8)$ & $9.4 \%(4.9-14.0)$ \\
\hline
\end{tabular}

All values are community-level means in children $<60$ months with $95 \%$ CI values.

* Using the WHO simplified grading system. ${ }^{11}$ 
TABLE 2

Nutritional assessment of children ages 6-60 months in 24 communities randomized (1:1) to annual or biannual mass azithromycin treatment in a cluster-randomized clinical trial

\begin{tabular}{|c|c|c|c|c|c|c|}
\hline \multirow[b]{2}{*}{ Measurement } & \multicolumn{2}{|c|}{ Annual treatment (12 communities) } & \multicolumn{2}{|c|}{ Biannual treatment (12 communities) } & \multirow[b]{2}{*}{ OR $(95 \% \mathrm{CI})$} & \multirow[b]{2}{*}{$P$ value } \\
\hline & Percent & Number/total & Percent & Number/total & & \\
\hline Wasting & 14.8 & $72 / 486$ & 11.6 & $63 / 545$ & $0.75(0.46-1.23)$ & 0.26 \\
\hline Low MUAC & 20.2 & $98 / 486$ & 18.5 & $101 / 545$ & $0.93(0.59-1.46)$ & 0.74 \\
\hline Stunting & 76.5 & $371 / 485$ & 74.5 & $406 / 545$ & $0.89(0.65-1.22)$ & 0.48 \\
\hline Underweight & 64.1 & $311 / 485$ & 59.5 & $324 / 545$ & $0.81(0.57-1.16)$ & 0.26 \\
\hline
\end{tabular}

communities than the annually treated communities in this restricted analysis (mixed effects linear regression, 0.49, 95\% $\mathrm{CI}=0.29-0.70, P<0001)$. In the biannually treated communities, individuals who participated in the program and received their assigned treatment at baseline had 35\% higher WHZ $(0.35,95 \% \mathrm{CI}=-0.008$ to $0.72, P=0.056)$ than those individuals who did not receive baseline treatment. Note that those individuals who missed their baseline treatment but received treatment at 6 months had a similar increase in their WHZ score $(0.34,95 \% \mathrm{CI}=-0.20$ to 0.71$)$, consistent with a dose response for each antibiotic treatment. In these same communities, individuals who received their assigned treatment two times (at baseline and 6 months) had WHZ scores $65 \%$ higher $(0.65,95 \% \mathrm{CI}=0.37-0.93, P<0001)$ than those individuals who received no treatment.

\section{DISCUSSION}

This cluster-randomized clinical trial in Niger of children ages 6-60 months shows that growth and nutrition are not different in communities randomized to a single mass azithromycin treatment versus communities randomized to two mass azithromycin treatments. We were unable to detect a difference in height, weight, and MUAC in the communities that received a single additional mass treatment.

With the analysis restricting inclusion to participants who received their prescribed antibiotics at baseline, we were unable to show a difference in WHZ scores between communities randomized to annual treatment and communities randomized to biannual treatment. Note that this restriction is a deviation from our primary pre-specified intention-to-treat analysis, where participants were not withdrawn after randomization for any reason. We are aware that withdrawing individuals from the study, even because of non-adherence, may offer bias of unknown magnitude and direction. ${ }^{21}$ Nevertheless, these restricted analyses can present an estimate of biological efficacy that intention-to-treat analyses may be unable to provide. ${ }^{22}$ For example, we detected a dose response in those individuals who received their assigned treatment, and each additional treatment (from zero treatments to one treatment and from one treatment to two treatments) resulted in a WHZ score that was approximately $30 \%$ higher.

Although we did not detect a difference between annual and biannual mass antibiotic treatments on anthropometry, this finding may be because of the following reasons. First, a single extra mass azithromycin treatment over the course of 1 year may not be sufficient to have an effect on growth. Second, this study was a cross-sectional study and did not follow communities longitudinally; a longitudinal study might be better able to detect a smaller effect size. Third, there is a seasonal component to wasting in Niger, with high prevalence from December to February (after the rainy season) and lower prevalence in October (in the dry season when our study took place).$^{20}$ Performing a study when wasting is at its lowest might make it more difficult to detect an effect of mass antibiotic treatment.

The outcome measures were performed 1 year after treatment in the annually treated communities and 6 months after treatment in the biannually treated communities by study design. In future studies, we plan to perform outcome measurements at the same time after treatment in compared communities to help with interpretation.

In conventional livestock production, antibiotics have been used to enhance weight gain and promote growth since the early $1950 \mathrm{~s}^{23}$ The use of antibiotics in food-producing animal agriculture results in healthier, more productive animals, lower disease incidence, and reduced morbidity and mortality, although this practice is controversial. ${ }^{24}$ The biological basis for the growth-promoting effects of oral antibiotics could be a reduction in intestinal microflora, which compete for nutrients, ${ }^{25}$ or treatment of subclinical infection. ${ }^{26,27}$ The Animal Health Institute (AHI) estimates that between 9\% and 17\% of all antibiotics sold in the United States for animals are for growth promotion or improved feed efficiency. ${ }^{23}$ Antibiotics are not currently prescribed for growth promotion in humans, although treatment of children with deworming drugs has been shown to increase weight in some studies. ${ }^{28}$ The mechanism

TABLE 3

Nutritional $z$ scores in children ages 6-60 months in 24 communities randomized (1:1) to annual or biannual mass azithromycin treatment in a cluster-randomized clinical trial

\begin{tabular}{|c|c|c|c|c|c|c|}
\hline \multirow[b]{2}{*}{ Metric } & \multicolumn{2}{|c|}{ Annual treatment (12 communities) } & \multicolumn{2}{|c|}{ Biannual treatment (12 communities) } & \multirow[b]{2}{*}{ Coefficient $(95 \% \mathrm{CI})^{*}$} & \multirow[b]{2}{*}{$P$ value } \\
\hline & $N$ & Mean & $N$ & Mean & & \\
\hline WHZ & 481 & $-0.89 \pm 1.30$ & 538 & $-0.78 \pm 1.08$ & $0.09(-0.16$ to 0.34$)$ & 0.48 \\
\hline MUACZ & 483 & $-1.25 \pm 1.01$ & 541 & $-1.20 \pm 0.93$ & $0.03(-0.18$ to 0.23$)$ & 0.81 \\
\hline HAZ & 482 & $-3.13 \pm 2.24$ & 541 & $-3.07 \pm 1.71$ & $0.07(-0.31$ to 0.45$)$ & 0.71 \\
\hline WAZ & 483 & $-2.44 \pm 1.45$ & 541 & $-2.23 \pm 1.24$ & $0.12(-0.15$ to 0.39$)$ & 0.38 \\
\hline
\end{tabular}

Numbers may be different because of some loss during field examination, and $z$ scores could not be calculated for children age 5 years at the time of anthropometry.

* Mixed effects linear regression was used with community as a random effect; coefficient reflects the change in $z$ score in the biannually treated arm relative to the annually treated arm. 
for the observed reduction in childhood mortality associated with mass azithromycin treatments is unknown, and it may be, in part, because of improved growth and nutrition.

Antibiotics do not provide a benefit for the treatment of undernutrition based on our study. Mass azithromycin treatments have proven to be very effective in programs for trachoma control, and the treatments are well-tolerated. ${ }^{29}$ Since 1999, over 225 million treatments of azithromycin have been donated through the International Trachoma Initiative for distribution by local partners in 19 countries. ${ }^{30}$ Investigation of positive and negative secondary effects associated with these treatments should be part of any mass treatment trial or program, particularly study of emerging antibiotic resistance. Although there is a large increase in the prevalence of resistance in nasopharyngeal pneumococcus after mass antibiotic use, ${ }^{31}$ this resistance drops quickly when mass distributions are discontinued. ${ }^{32}$ Nevertheless, a strategy that provides antibiotics to large numbers of children to prevent non-specific infectious diseases to improve growth parameters is currently not advised based on our study.

In summary, we were unable to detect differences in anthropometry measurements in communities randomized to receive an extra mass azithromycin distribution; there were fewer cases of stunting and wasting with the extra treatment, but the result was not significant. There may not be an association between antibiotics and enhanced growth, or this trial may not have been powerful enough to detect an association. Larger studies, longer studies, or longitudinal measurements of growth may be able to find a beneficial effect of antibiotics on growth if it exists.

Received May 4, 2012. Accepted for publication September 4, 2012. Published online December 3, 2012.

Acknowledgments: The authors thank the data and safety monitoring committee, including Douglas Jabs, MD, MBA (chair); Antoinette Darville, MD; Maureen Maguire, PhD; and Grace Saguti, MD, who were generous with their time and advice and met before and during the study. The authors thank Kurt Dreger, who designed and helped maintain the database, and all of our colleagues in Niger at Programme National de Lutte Contre la Cécité who helped perform the study, including Yacouba Moussa, Abdoul Karim Morou, Hadjara Soumana, Ali Borno, Hamida Halirou, Hassane Seyni, Alhassane Yahaya Agali, Hadiza Dan Sounsou, Chano Hamidan, Adamou Madougou, Diallo Salamatou, and Omar Haougui. The Bill and Melinda Gates Foundation (Grant 48027) was the main supporter of this trial. This project was also supported by National Institutes of Health/National Eye Institute Grant K23 EYO19881-01 and National Institutes of Health/NCRR/OD University of California at San Francisco CTSI Grant KL2 RR024130. The funders had no role in study design, data collection and analysis, decision to publish, or preparation of the manuscript. This trial is registered at ClinicalTrials.gov (NCT00792922).

Financial support: This work was supported by The Bill and Melinda Gates Foundation Grant 48027, National Institutes of Health/National Eye Institute Grant K23 EYO19881-01, and National Institutes of Health/University of California at San Francisco Clinical and Translational Science Institute Grant KL2 RR024130.

Disclaimer: The authors have declared that no competing interests exist.

Authors' addresses: Abdou Amza, Boubacar Kadri, and Baido Nassirou, Université Abdou Moumouni de Niamey, Programme National de Lutte Contre la Cécité, Niamey, Niger, E-mails: dr.amzaabdou@gmail.com, boubacarkadri@gmail.com, and nasbeido@yahoo.fr. Nicole E. Stoller, Sun N. Yu, Zhaoxia Zhou, Travis C. Porco, Thomas M. Lietman, and Bruce D. Gaynor, F. I. Proctor Foundation, University of California, San Francisco, CA, E-mails: Nicole.Stoller@ucsf.edu, Sun.Yu@ucsf.edu, Zhaoxia.Zhou@ucsf.edu, Travis.Porco@ucsf.edu, Tom.Lietman@ucsf .edu, and Bruce.Gaynor@ucsf.edu. Sheila K. West, Dana Center for Preventive Ophthalmology, Wilmer Eye Institute, Johns Hopkins University, Baltimore, MD, E-mail: shwest@jhmi.edu. David C. W. Mabey and Robin L. Bailey, Department of Infectious and Tropical Diseases, London School of Hygiene and Tropical Medicine, London, United Kingdom, E-mails: Robin.Bailey@ucsf.edu and David.Mabey@ lshtm.ac.uk. Jeremy D. Keenan, F. I. Proctor Foundation, Department of Ophthalmology, University of California, San Francisco, CA, E-mail: Jeremy.Keenan@ucsf.edu.

\section{REFERENCES}

1. Scrimshaw NS, Taylor CE, Gordon JE, 1968. Interaction of Nutrition and Infection. World Health Organization Monograph Series 57. Geneva: World Health Organization.

2. Caulfield LE, de Onis M, Blossner M, Black RE, 2004. Undernutrition as an underlying cause of child deaths associated with diarrhea, pneumonia, malaria, and measles. Am J Clin Nutr 80: 193-198.

3. Katona P, Katona-Apte J, 2008. The interaction between nutrition and infection. Clin Infect Dis 46: 1582-1588.

4. Lode H, Borner K, Koeppe P, Schaberg T, 1996. Azithromycinreview of key chemical, pharmacokinetic and microbiological features. J Antimicrob Chemother 37 (Suppl C): 1-8.

5. Fry AM, Jha HC, Lietman TM, Chaudhary JS, Bhatta RC, Elliott J, Hyde T, Schuchat A, Gaynor B, Dowell SF, 2002. Adverse and beneficial secondary effects of mass treatment with azithromycin to eliminate blindness due to trachoma in Nepal. Clin Infect Dis 35: 395-402.

6. Whitty CJ, Glasgow KW, Sadiq ST, Mabey DC, Bailey R, 1999. Impact of community-based mass treatment for trachoma with oral azithromycin on general morbidity in Gambian children. Pediatr Infect Dis J 18: 955-958.

7. Sadiq ST, Glasgow KW, Drakeley CJ, Muller O, Greenwood BM, Mabey DC, Bailey RL, 1995. Effects of azithromycin on malariometric indices in The Gambia. Lancet 346: 881-882.

8. Keenan JD, Ayele B, Gebre T, Zerihun M, Zhou Z, House JI, Gaynor BD, Porco TC, Emerson PM, Lietman TM, 2011. Childhood mortality in a cohort treated with mass azithromycin for trachoma. Clin Infect Dis 52: 883-888.

9. Porco TC, Gebre T, Ayele B, House J, Keenan J, Zhou Z, Hong KC, Stoller N, Ray KJ, Emerson P, Gaynor BD, Lietman TM, 2009. Effect of mass distribution of azithromycin for trachoma control on overall mortality in Ethiopian children: a randomized trial. JAMA 302: 962-968.

10. Stare D, Harding-Esch E, Munoz B, Bailey R, Mabey D, Holland M, Gaydos C, West S, 2011. Design and baseline data of a randomized trial to evaluate coverage and frequency of mass treatment with azithromycin: the Partnership for Rapid Elimination of Trachoma (PRET) in Tanzania and The Gambia. Ophthalmic Epidemiol 18: 20-29.

11. Thylefors B, Dawson CR, Jones BR, West SK, Taylor HR, 1987. A simple system for the assessment of trachoma and its complications. Bull World Health Organ 65: 477-483.

12. World Health Organization, 2010. Report of the Fourteenth Meeting of the WHO Alliance for Global Elimination of Blinding Trachoma. Geneva: World Health Organization.

13. Team RDC, 2008. R: A Language and Environment for Statistical Computing. Vienna, Austria: R Foundation for Statistical Computing.

14. Amza A, Kadri B, Nassirou B, Stoller NE, Yu SN, Zhou Z, Chin S, West SK, Bailey RL, Mabey DCW, Keenan JD, Porco TC, Lietman TM, Gaynor BD; PRET Partnership, 2012. Community risk factors for ocular chlamydia infection in Niger: pretreatment results from a cluster-randomized trachoma trial. PLoS Negl Trop Dis 6: e1586.

15. World Health Organization, 2008. WHO Child Growth Standards: Training Course on Child Growth Assessment. Geneva: World Health Organization.

16. World Health Organization, 2010. WHO Anthro for Personal Computers, Version 3.2.2, 2011: Software for Assessing Growth and Development of the World's Children. Geneva: World Health Organization. 
17. Labrique AB, Christian $\mathrm{P}$, Klemm RD, Rashid M, Shamim AA, Massie A, Schulze K, Hackman A, West KP Jr, 2011. A clusterrandomized, placebo-controlled, maternal vitamin A or betacarotene supplementation trial in Bangladesh: design and methods. Trials 12: 102 .

18. Group WMGRS, 2006. WHO Child Growth Standards: Length/ Height-for-Age, Weight-for-Age, Weight-for-Length, Weightfor-Height and Body Mass Index-for-Age: Methods and Development. Geneva: World Health Organization.

19. Gibson RS, 2005. Principles of Nutritional Assessment. New York: Oxford University Press.

20. Isanaka S, Nombela N, Djibo A, Poupard M, Van Beckhoven D, Gaboulaud V, Guerin PJ, Grais RF, 2009. Effect of preventive supplementation with ready-to-use therapeutic food on the nutritional status, mortality, and morbidity of children aged 6 to 60 months in Niger: a cluster randomized trial. JAMA 301: 277-285.

21. May GS, DeMets DL, Friedman LM, Furberg C, Passamani E, 1981. The randomized clinical trial: bias in analysis. Circulation 64: 669-673.

22. Sommer A, Zeger SL, 1991. On estimating efficacy from clinical trials. Stat Med 10: 45-52.

23. Viola C, DeVincent SJ, 2006. Overview of issues pertaining to the manufacture, distribution, and use of antimicrobials in animals and other information relevant to animal antimicrobial use data collection in the United States. Prev Vet Med 73: 111-131.

24. Oliver SP, Murinda SE, Jayarao BM, 2011. Impact of antibiotic use in adult dairy cows on antimicrobial resistance of veterinary and human pathogens: a comprehensive review. Foodborne Pathog Dis 8: 337-355.

25. Visek WJ, 1978. The mode of growth promotion by antibiotics. J Anim Sci 46: 1447-1469.
26. Dibner JJ, Richards JD, 2005. Antibiotic growth promoters in agriculture: history and mode of action. Poult Sci 84: 634-643.

27. Shryock TR, Page SW, 2007. Growth promotion uses of antimicrobial agents. In: S Giguere, JF Prescott, JD Baggot, RD Walker, \& PM Dowling, eds., Antimicrobial Therapy in Veterinary Medicine ( $4^{\text {th }}$ ed, 389-404). Ames, IA: WileyBlackwell Publishing.

28. Taylor-Robinson DC, Maayan N, Soares-Weiser K, Donegan S, Garner P, 2012. Deworming drugs for soil-transmitted intestinal worms in children: effects on nutritional indicators, haemoglobin and school performance. Cochrane Database Syst Rev 7: CD000371.

29. Ayele B, Gebre T, House JI, Zhou Z, McCulloch CE, Porco TC, Gaynor BD, Emerson PM, Lietman TM, Keenan JD, 2011. Adverse events after mass azithromycin treatments for trachoma in Ethiopia. Am J Trop Med Hyg 85: 291-294.

30. International Trachoma Initiative, 2011. International Trachoma Initiative: Frequently Asked Questions. Decatur, GA: International Trachoma Initiative.

31. Skalet AH, Cevallos V, Ayele B, Gebre T, Zhou Z, Jorgensen JH, Zerihun M, Habte D, Assefa Y, Emerson PM, Gaynor BD, Porco TC, Lietman TM, Keenan JD, 2010. Antibiotic selection pressure and macrolide resistance in nasopharyngeal Streptococcus pneumoniae: a cluster-randomized clinical trial. PLoS Med 7: e1000377.

32. Haug S, Lakew T, Habtemariam G, Alemayehu W, Cevallos V, Zhou Z, House J, Ray K, Porco T, Rutar T, Keenan J, Lietman TM, Gaynor BD, 2010. The decline of pneumococcal resistance after cessation of mass antibiotic distributions for trachoma. Clin Infect Dis 51: 571-574. 